\title{
PCAST reincarnation brings promise for US materials science community
}

\author{
whitehouse.gov/ostp
}

$\mathrm{T}^{\mathrm{s}}$ he materials research community is looking with anticipation at the reinstatement of the US President's Council of Advisors on Science and Technology (PCAST), announced last October. Started in 1990 by President George H.W. Bush, PCAST has advised the president "on matters involving science and technology policy" in every administration since. In that role, it not only has the power to drive the direction of US science and technology, but has a say in industry and national security.

Reinstating the council signals a significant step forward for the state of science policy at the White House and for other policymakers, says David P. Norton, professor of materials science and engineering at the University of Florida and chair of the Government Affairs Committee at the Materials Research Society (MRS).

Alan Hurd of the National Security Education Center at the Los Alamos National
Laboratory, and former Franklin Fellow for the Science and Technology Adviser to the Secretary of State, credits Kelvin K. Droegemeier with resurrecting PCAST. As the Director of the Office of Science and Technology Policy (OSTP), Droegemeier will lead the council. Before becoming the president's science advisor, Droegemeier researched extreme weather, numerical weather prediction, and data assimilation at The University of Oklahoma.

The stated focus on nanotechnology, artificial intelligence, and quantum information science, and the far greater number of members in industry compared to academia stood out in PCAST's introductory announcement.

"It is absolutely necessary but not sufficient to have industry as PCAST members," Hurd says. "This current roster is completely insufficient with its lack of academics so far." It is a sentiment, he says, that he arrived at after discussions

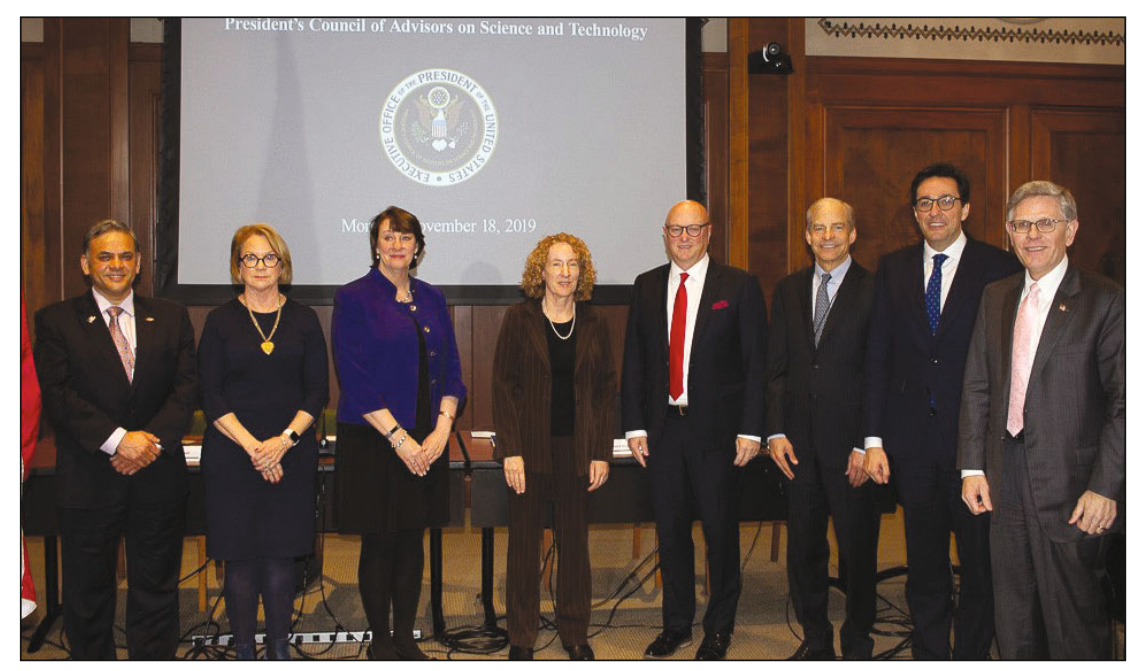

Members of the President's Council of Advisors on Science and Technology (from left to right): A.N. Sreeram, Dow Chemical Company; Catherine P. Bessant, Bank of America; Sharon Hrnykow, Cyclo Therapeutics, Inc.; K. Birgitta Whaley, University of California, Berkeley; Shane Wall, HP Labs, HP Inc.; H. Fisk Johnson, S.C. Johnson \& Son, Inc.; Dario Gil, IBM T.J. Watson Research Center; together with Kelvin K. Droegemeier, Director of the White House Office of Science and Technology Policy (OSTP), who will lead the council. Photo taken after the swearing-in ceremony on November 18, 2019. Photo credit: @WHOSTP (White House OSTP twitter handle). with colleagues. Hurd thinks it is a positive that high-tech companies are represented, but fears the dearth of academic members means their voice will be muted. "Most of the basic research is coming out of academia and the national labs - that representation is important," he added.

The feeling that PCAST's membership is skewed too heavily to industry is not universal, however. "We're not all basic research scientists in MRS," Norton says. "I really don't see [academia and industry] as being competitors." $\mathrm{He}$ believes the current PCAST roster is filled with "outstanding individuals at the top of their fields," and that Droegemeier's leadership will ensure academia's voice will be heard on the council.

MRS is indifferent about the balance of PCAST appointees from industry or academia, according to MRS Director of Government Affairs, Damon Dozier. But that does not stop him from advocating individual appointees' virtues as proponents for the materials science community. Dozier points to K. Birgitta Whaley, who is an expert in quantum information and Dario Gil, who has worked in all three target fields, as examples of PCAST appointees providing the voice the materials science community needs. Furthermore, Dozier says, more members may be coming. "Right now, we simply don't know."

There is little disagreement, however, that the choice to push quantum IT, AI, and nanotechnology is good for the US materials research community. According to Norton, these areas are "clearly deserving of specific attention at this point." These technologies will be "remarkably important in the next decade," Hurd says. AI and machine learning are expected to change how science will get done, he says.

The focus on quantum IT and AI was predictable, according to Dozier. 
Congress and the executive branch have favored policies that foster these technologies, he says. Perhaps chief among this legislation is the National Quantum Initiative Act, which became law in December 2018 (see MRS Bulletin, March 2019, p. 158). Dozier notes there have been numerous efforts to spark more research in quantum IT and AI at the Department of Energy, the Department of Defense, the National Science Foundation, and the National Institute of Standards and Technology.

Part of the reason for the intense focus on quantum IT and AI is the concern that US research is falling behind the pace of research happening in other parts of the world. "There is clearly an important materials community in Asia that we can no longer ignore," Hurd says. China is near completing its China Spallation Neutron Source installation, he says. Some European nations are also doing impressive research, according to Hurd. "Is the United States 'keeping up'? No," Hurd says. "Are we still competitive? Yes."

"Chinese investments are paying off," Norton says. Though PCAST has no ability to provide funding, Norton wants PCAST to help make the case for the federal government to provide the materials science community with more research dollars.

Norton believes PCAST's composition will benefit the materials science community. He points to how the federal government has spurred past game-changing developments like transportation,

\section{MEMBERS APPOINTED TO PCAST}

\section{FROM ACADEMIA}

- K. Birgitta Whaley, Director of the Berkeley Quantum Information and Computation Center, University of California, Berkeley

(intent to appoint)

- Shannon Blunt, Professor of Electrical Engineering and Director of the Radar Systems \& Remote Sensing Laboratory, University of Kansas

- Dorota Grejner-Brzezinska, Associate Dean for Research at the College of Engineering, The Ohio State University

\section{FROM INDUSTRY}

- Catherine P. Bessant, Chief Operations and Technology Officer, Bank of America

- Dario Gil, Director of IBM Research, IBM T.J. Watson Research Center

- Sharon Hrnykow, Chief Scientific Officer, Cyclo Therapeutics, Inc.

- H. Fisk Johnson, Chairman and CEO, and Chairman of the Board, S.C. Johnson \& Son, Inc.

- A.N. Sreeram, Senior Vice President and Chief Technology Officer, Dow Chemical Company

- Shane Wall, Chief Technology Officer and Global Head of HP Labs, HP Inc.

communication, and computers. "I think the materials research community should be encouraged by that." Close attention should be paid to how the National Science Foundation, the National Institute of Standards and Technology, and the Departments of Energy and Defense are supported in the near future.

Hurd thinks PCAST's stated focus on quantum IT, AI, and nanotechnology are good for the materials science community, but that there "should be a little more breadth than that." He would also like to see more focus on biomaterials. He noted an artificial muscle being developed at
The University of Texas at Dallas, by Ray Baughman. Hurd likened it to the old, propeller airplanes made of balsa wood that are wound with a rubber band. The artificial muscle remains in a supercoiled state until interrupted by a small change in temperature.

With or without an explicit connection to biomaterials, the return of PCAST means a science connection between the federal government, industry, and academia. PCAST had been idle for two years. Now, there is a designated group to take up the leadership mantle again.

Clinton Parks

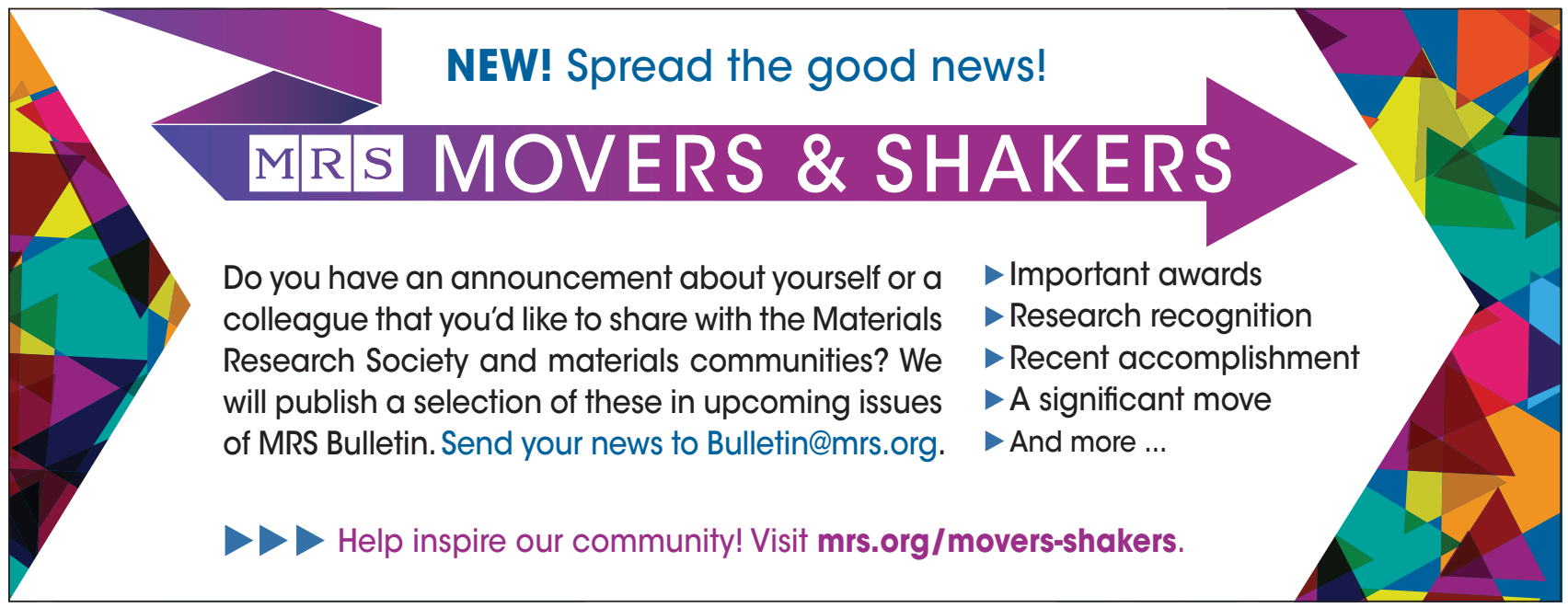

